\title{
DESAIN INFRASTRUKTUR JARINGAN LINK MICROWAVE ANTAR KAMPUS POLITEKNIK NEGERI UJUNG PANDANG
}

\author{
Rini Nur ${ }^{1}$, Irawan ${ }^{2}$, Rahmi Bekarti ${ }^{3}$ \\ Jurusan Teknik Elektro, Politeknik Negeri Ujung Pandang ${ }^{1,2,3}$ \\ email: rini@poliupg.ac.id ${ }^{1}$, irawan@poliupg.ac.id ${ }^{2}$, rahmi.bekarati@gmail.com³
}

\begin{abstract}
ABSTRAK
Politeknik Negeri Ujung Pandang (PNUP) sebagai sebuah institusi pendidikan memanfaatkan TIK untuk menunjang kegiatan akademik dan administrasinya. Saat ini PNUP telah memiliki dua buah kampus sehingga dibutuhkan interkoneksi infrastruktur jaringan antar lokasi tersebut. Pada penelitian ini dilakukan analisa dan desain link microwave sebagai infrastruktur jaringan antar kampus. Penelitian meliputi survey, perancangan melalui hasil analisa dengan metode line of sight melalui studi topografi dan analisa link budget menggunakan Aplikasi Google Earth, Pathloss, dan perangkat GPS. Desain ketinggian antena menggunakan tower Jurusan Elektro Kampus 1 setinggi $20 \mathrm{~m}$ dan tiang antena titik akhir di atas Gedung Jurusan Elektro Kampus 2 setinggi 3,35 m. Performansi komunikasi melalui jalur link microwave tersebut diatas memiliki kualitas yang sangat baik dimana parameter komunikasi terpenuhi adalah FSL $128.75 \mathrm{~dB}$, EIRP $45.60 \mathrm{dBm}$, RSL -57.65 $\mathrm{dBm}$, SOM $12.46 \mathrm{~dB}$. Desain yang dihasilkan pada penelitian ini adalah desain infrastruktur link microwave yang memenuhi persyaratan jaminan kualitas performansi komunikasi sehingga dapat menjadi dasar bagi pengembangan infrastruktur jaringan antar kampus PNUP.
\end{abstract}

Kata Kunci : Link Bugdet, Line Of Sight, Link Microwave

\section{PENDAHULUAN}

Perguruan tinggi dituntut untuk bisa menjalin komunikasi dan interaksi yang baik antar unit-unitnya dan senantiasa meningkatkan proses-proses internalnya agar bisa menghasilkan produk yang berkualitas. Dalam hal ini TIK adalah faktor yang sangat strategis. TIK tidak hanya berperan membantu mempercepat, mempermudah, dan meningkatkan akurasi proses-proses akademik dan administratif, tetapi juga memungkinkan terjadinya perbaikan-perbaikan substansial melalui solusi-solusi yang inovatif.

Salah satu persoalan dalam pengembangan TIK adalah ada tidaknya perencanaan. Perencanaan pengembangan teknologi dan infrastrukstur yang baik akan menghasilkan penerapan/ implementasi teknologi TIK yang optimal. Untuk itu dibutuhkan suatu desain yang mempertimbangkan segala aspek yang terkait dengan teknologi tersebut.

Politeknik Negeri Ujung Pandang (selanjutnya disebut PNUP) sebagai salah satu perguruan tinggi di kota Makassar yang semakin berkembang, saat ini telah menambah lokasi kampus menjadi dua kampus yang terpisah. Kampus 1 PNUP yang berada di kecamatan Tamalanrea berjarak kurang lebih sekitar $4.91 \mathrm{~km}$ dari kampus 2 yang berada di kecamatan Moncongloe, Kab.Maros. 
PNUP memanfaatkan TIK untuk menunjang kegiatan akademik dan administrasinya sehingga dibutuhkan interkoneksi infrastruktur jaringan antar Kampus 1 dan Kampus 2 PNUP tersebut.

Salah satu alternatif untuk memenuhi kebutuhan tersebut yaitu dengan menerapkan link microwave sebagai salah satu solusinya. Jaringan wireless digunakan karena lokasi kedua kampus tersebut letaknya terpisah dimana sulit untuk penerapan instalasi kabel.

Pada penelitian ini dilakukan survey, perencanaan dengan metode analisa line of sight melalui studi topografi dan analisa link budget menggunakan Aplikasi Google Earth, Pathloss, dan perangkat GPS.

Hasil dari studi ini menjadi dasar desain implementasi link microwave point to point antara Kampus 1 dan Kampus 2 PNUP. Desain yang dihasilkan pada penelitian ini adalah desain infrastruktur link microwave yang memenuhi persyaratan jaminan kualitas performansi komunikasi yang baik dan secara tidak langsung juga dapat mengoptimalkan nilai investasi implementasinya sehingga diharapkan kedepannya dapat menjadi dasar implementasi atau penerapan jaringan antar Kampus 1 dan Kampus 2 PNUP.

\section{TINJAUAN PUSTAKA}

\subsection{Teknologi Informasi pada Perguruan Tinggi}

Institusi perguruan tinggi adalah sebuah organisasi yang menggunakan teknologi informasi dalam mendukung proses bisnisnya. Dalam organisasi perguruan tinggi, lebih menekankan peranan teknologi informasi dalam mendukung kegiatan akademik, operasional, keuangan dan manajemen perguruan tinggi, sehingga diharapkan tercapainya keselarasan investasi teknologi yang dikeluarkan dengan kebutuhan bisnis yang ada dalam perguruan tinggi (Yunis,dkk,2009).

Sistem informasi dalam suatu perguruan tinggi minimal terdiri atas pengumpulan data, analisis, penyimpanan, pengambilan kembali data (retrieval), presentasi data dan informasi serta komunikasi dengan pihak berkepentingan yang dibangun secara terpusat di tingkat perguruan tinggi dan atau terdistribusi pada unit-unit terkait. Data dan informasi yang dikelola oleh perguruan tinggi dapat meliputi akademik, kemahasiswaan, sumberdaya manusia, prasarana dan sarana, administrasi dan keuangan serta data lain yang dianggap perlu untuk kepentingan berbagai pihak. Dalam berbagai hal, perguruan tinggi harus dapat memanfaatkan sistem informasi yang dimilikinya untuk memelihara komunikasi dan koordinasi internal serta kerjasama dengan institusi lain, pemerintah, alumni, perusahan/industri atau masyarakat luas.

Berkenaan dengan perkembangan teknologi informasi yang sangat cepat maka perguruan tinggi harus mampu melakukan pengelolaan yang profesional serta pemutahiran terhadap piranti keras dan lunak, sumber daya manusia serta organisasi pengelola untuk menjamin pertumbuhan sistem informasi yang telah dibangun tersebut. Perguruan tinggi juga harus menjamin akses bagi mahasiswa, staf dan sivitas akademika lainnya untuk memanfaatkan keberadaan sistem informasi tersebut (BAN PT, 2007).

Suatu sistem informasi sebuah perguruan tinggi harus dibangun dengan perencanaan yang matang. Kurangnya 
perencanaan di dalam proses pengembangan sistem informasi yang tepat akan menghambat dalam melengkapi arah strategi suatu perguruan tinggi. Sistem informasi yang baik harus melihat dari berbagai sudut pandang dalam suatu pengembangan sistem, dimulai dari mendefinisikan arsitektur data, arsitektur aplikasi serta mendefinisikan arsitektur teknologi yang mendukung jalannya sistem informasi tersebut (Marissa, 2012).

\subsection{Desain Jaringan Link Microwave}

\subsubsection{Analisa Line of Sight}

Mekanisme pembuatan gelombang radio salah satunya adalah Line Of Sight (LOS) yang merupakan lintasan gelombang radio yang mengikuti garis pandang. Selain lintasan yang diharapkan dalam perencanaan LOS, pengalokasian frekuensi kerja dan desain link budget pada sistem telekomunikasi juga perlu diperhatikan. Perhitungan link budget digunakan untuk memastikan bahwa level daya batas ambang agar sinyal cukup kuat untuk diterima dengan baik dan nilai availability sebagai tolak ukur untuk memastikan sistem dapat berfungsi dengan baik (Utami dkk, 2014).

Pemilihan jalur komunikasi dilakukan berdasarkan hasil study map dengan menggunakan peta topografi kontur bumi. Hasil dari field survey maupun digital map terdiri atas koordinat site, evaluasi permukaan tanah (altitude), kondisi topografi lintasan link apakah daerah pegunungan, dataran rendah, atau perairan, tinggi tower yang akan digunakan dan sebagainya. Pada tahapan study map meliputi :

a. Pemilihan lokasi titik awal dan akhir. b. Data Koodinat site yang diperoleh dari GPS (Global Positioning System).

c. Data koordinat secara keseluruhan dari lintasan link dapat diperoleh menggunakan aplikasi Map seperti Google Earth.

d. Perhitungan dengan menggunakan aplikasi link bugdet seperti Software Pathloss Versi 4.0

\subsubsection{Analisa Link Budget}

Link budget merupakan sebuah cara untuk menghitung mengenai semua parameter dalam transmisi sinyal, mulai dari gain dan losses dari $\mathrm{Tx}$ sampai $\mathrm{Rx}$ melalui media transmisi. Dalam hal ini perhitungan dengan media transmisi Wifi.

Link budget ini dihitung berdasarkan jarak antara transmitter (Tx) dan receiver $(\mathrm{Rx})$. Link budget juga dihitung karena adanya penghalang antara $\mathrm{Tx}$ dan $\mathrm{Rx}$ missal gedung atau pepohonan. Link budget juga dihitung dengan melihat spesifikasi yang ada pada antenna.

Saat proses transmisi data terjadi melewati ruang udara bebas, timbul redaman berupa free space loss (FSL) yang mengakibatkan adanya penurunan daya gelombang radio, yang dipengaruhi oleh besar frekuensi dan jarak antara titik pengirim dan penerima.Perhitungan selanjutnya adalah untuk memastikan bahwa level

daya penerimaan lebih besar atau sama dengan level daya threshold (RSL $\geq \mathrm{Rth}$ ) agar sinyal cukup kuat untuk diterima receiver dengan baik. Perhitungan diawali dengan menghitung besaran yang menyatakan kekuatan daya pancar antena berupa EIRP (Effective Isotropic Radiated Power).

Setelah menghitung FSL dan EIRP, kemudian menghitung RSL (Receive 
Signal Level). Receive Signal Level adalah level sinyal yang diterima di penerima dan nilainya harus lebih besar dari sensitifitas perangkat penerima (RSL $\geq$ Rth). Sensitifitas perangkat penerima merupakan kepekaan suatu perangkat pada sisi penerima yang dijadikan ukuran threshold.

Setelah hasil RSL sudah diketahui maka selanjutnya menghitung SOM (System Operating Margin) untuk meyakinkan bahwa sistem yang dirancang akan bekerja secara benar. Pada dasarnya System Operating Margin (SOM) menghitung selisih antara sinyal yang di terima dengan sensitifitas penerima

\section{METODE PENELITIAN}

Tahapan penelitian desain infrastruktur antar kampus ini khususnya jaringan link microwave antar kampus Politeknik Negeri Ujung Pandang terdiri dari dua tahap yang diuraikan sebagai berikut :

\subsection{Survey Lokasi}

pada tahap ini dilakukan survey lokasi, untuk menentukan beberapa alternatif potensi lokasi penempatan tower antena baik disisi Kampus 1 maupun di sisi Kampus 2 PNUP yang nantinya akan dianalisa untuk memperoleh pilihan lokasi terbaik.

\subsection{A n a lis a}

a. Analisa Line of Sight menggunakan metode line of sight/studi topografi untuk mengetahui kontur bumi dari beberapa jalur alternatif antar kedua kampus serta posisi penempatan dan ketinggian antena yang tepat di kedua lokasi kampus.

- Pada tahap ini dilakukan pengukuran ketinggian, koordinat lintang dan bujur dari semua potensi lokasi tersebut.
- Pengukuran ketinggian, koordinat lintang dan bujur dari titik-titik lokasi sepanjang jalur antar Kampus 1 dan Kampus 2 PNUP

- Mempersiapkan peta digital/digital map lokasi.

- Semua data dan digital map tersebut menjadi input bagi software/aplikasi Google Earth yang akan menampilkan gambar kontur bumi yang digunakan untuk analisa link topografi/line of sight.

- Analisa topografi/line of sight menggunakan Aplikasi PathLoss akan menghasilkan : gambar kontur bumi, petunjuk adanya penghalang, titik lokasi terbaik untuk penempatan tower antena pada kedua kampus dari beberapa alternatif lokasi, serta penetuan ketinggian dan pengarahan antenna terbaik yang menjamin komunikasi antar kedua kampus tidak mendapat hambatan/penghalang.

b. Analisa Link Bugdet menggunakan metode link budget/perhitungan /kalkulasi keandalan komunikasi.

- Pada bagian ini dilakukan perhitungan-perhitungan baik manual maupun menggunakan software PathLoss untuk memperoleh nilai-nilai parameterparameter komunikasi yang akan dicapai jika menggunakan jalur yang sudah diperoleh dari studi topografi pada tahap sebelumnya. Nilai parameter-parameter yang akan dihasilkan : FSL, EIRP, RSL dan SOM.

- Kombinasi dari semua paramater tersebut akan menghasilkan nilai SOM (System Operation Margin) yang akan dibandingkan dengan 
SOM standar sebagai patokan kualitas komunikasi yang baik.

\subsection{Desain Sistem}

Dari hasil analisa-analisa di atas sudah dapat ditentukan model dan spesifikasi lokasi dan infrastrukturnya yaitu : informasi topografi, titik lokasi dan ketinggian antena pada masing-masing kampus, profil jalur antar kedua kampus, spesifikasi perangkat komunikasi dan nilai-nilai parameter komunikasi yang dituangkan dalam bentuk gambar desain yang akan menjadi dasar/referensi yang tepat bagi implementasi interkoneksi tersebut.

Secara singkat metode dan tahapan dan hasil setiap tahapan penelitian digambarkan pada mind map seperti pada Gambar 3.1.

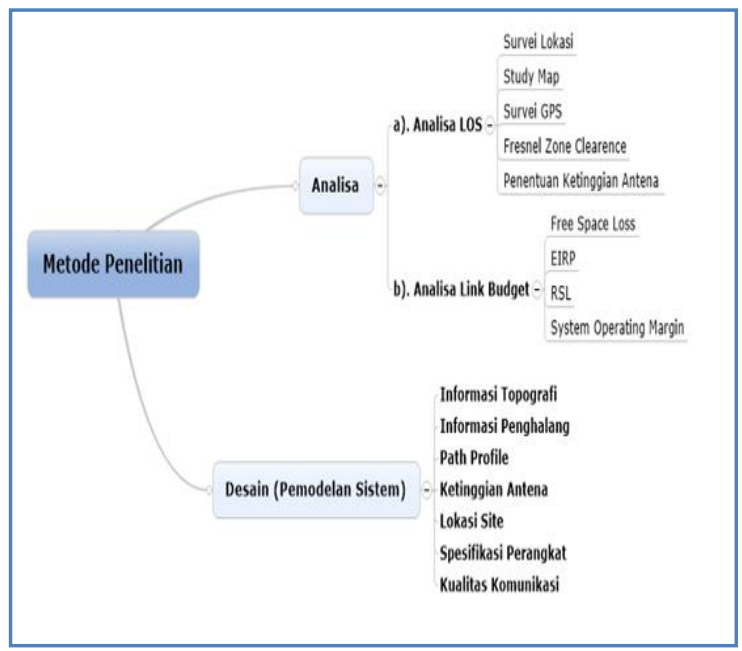

Gambar 3.1. Tahapan Penelitian Desain Infrastruktur Jaringan Link Microwave Antar Kampus PNUP

\section{HASIL DAN PEMBAHASAN}

\subsection{Survey Lokasi}

Dari hasil survey lokasi, ada tiga potensi titik yang dapat dijadikan sebagai titik awal penempatan tower di kampus PNUP yaitu Ruang Server, Jurusan Administrasi, dan Tower di Jurusan
Teknik Elektro di Kampus 1. Sedangkan yang akan dijadikan titik akhir yaitu Gedung Jurusan Teknik Elektro di Kampus 2. Pemilihan titik awal di dekat Ruang Server karena ruang ini merupakan lokasi server-server PNUP yang mengelola sistem informasi dan koneksi internet. Tentunya akan lebih menghemat penggunaan kabel yang akan digunakan. Titik awal pada Jurusan Administrasi juga dipilih sebagai alternatif karena memiliki gedung yang tinggi jika dibandingkan dengan gedung yang lainnya.

Titik awal pada Jurusan Elektro juga dipilih karena di Jurusan terdapat fasilitas bangunan tower yang cukup tinggi $( \pm 20 \mathrm{~m})$ dan juga sudah ada jalur fiber optik dari Jurusan Elektro ke Ruang Server. Puncak Gedung Elektro di Kampus 2 dipilih sebagai titik akhir karena dari hasil survei, terlihat bahwa lebih mudah menempatkan perangkat microwave ada disana. Selanjutnya Jalur antara Ruang Server Kampus 1 - Gedung Elektro Kampus 2 disebut Jalur 1, jalur antara Jurusan Administrasi Kampus 1 - Gedung Elektro Kampus 2 disebut Jalur 2, sedangkan untuk Tower di Jurusan Elektro Kampus 1 - Gedung Elektro Kampus 2 selanjutnya disebut Jalur 3.

\subsection{Analisa Line Of Sight}

Study map dilakukan dengan menggunakan aplikasi Google Earth. Dengan menggunakan peta Google Earth dapat diketahui kondisi profil antara titik nominal bumi tersebut (kontur permukaan tanah) serta dapat mengetahui kemungkinan penghalang yang terjadi antar kedua site.

Pada aplikasi Google Earth yang dilakukan adalah menandai titik awal dan titik akhir serta titik-titik diantara 
keduanya setiap $100 \mathrm{~m}$ sehingga diperoleh data garis lintang, garis bujur, ketinggian dari permukaan laut dari lokasi-lokasi tersebut. Dengan diketahui kedua titik nominal tersebut dapat ditarik garis lurus imaginer untuk mengetahui jarak kedua jalur tersebut.

Hasilnya sebagai berikut :

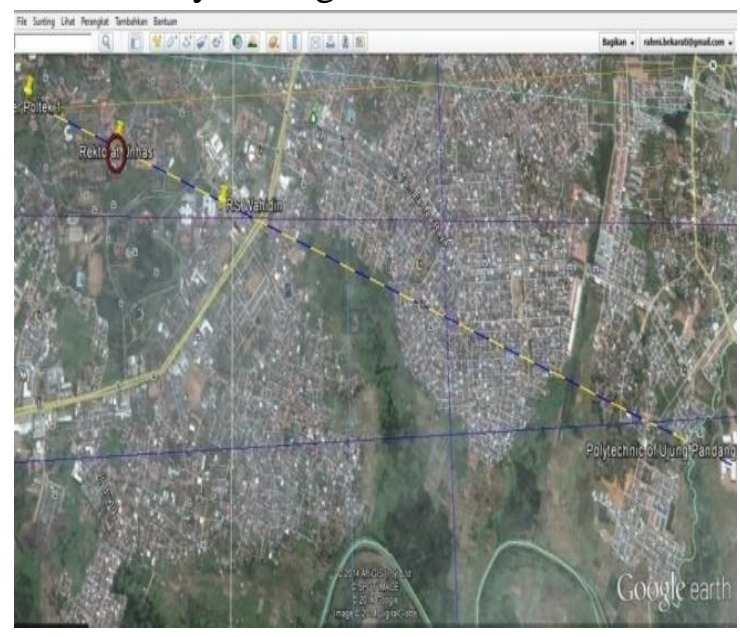

Gambar 4.2 Hasil Terrain Marking Jalur 2

Dari Gambar 4.2 terlihat pada Jalur 2 terdapat penghalang diantara kedua site tersebut yaitu Gedung Rektorat Unhas dengan ketinggian sekitar $28 \mathrm{~m}$ dan Gedung Private Care Center dengan ketinggian $32 \mathrm{~m}$.

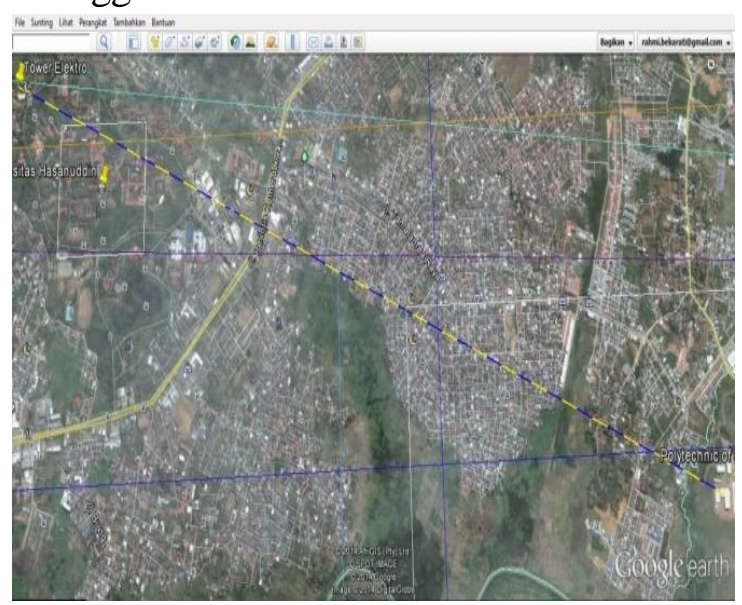

Gambar 4.3 Hasil Terrain Marking Jalur 3

Dari Gambar 4.3 terlihat pada Jalur 3 tidak terdapat penghalang diantara kedua site tersebut.
Data yang diperoleh dari aplikasi Google Earth akan dimasukkan lagi ke Software Pathloss untuk menganalisa kondisi LoS dengan demikian diperoleh data topografi yang diperoleh dari Google Earth dan kemudian dibandingkan dengan data dari pengukuran GPS

\section{Perhitungan Fresnel Zone dan ketinggian Antena}

Dengan mengetahui letak penghalang dan kondisi topografi antara kedua titik maka dapat ditentukan ketinggian minimum antenna yang akan digunakan untuk membuat titik antara kedua site tersebut memenuhi kriteria line of sight. Kondisi ini akan menjamin bebas dari segala bentuk penghalang yang dapat menyebabkan pembelokan, penghamburan, maupun perusakan sinyal yang dikirim oleh pemancar sehingga daya yang diterima sisi penerima tidak dapat optimum dan diprediksi nilainya.

Daerah Fresnel adalah daerah atau zona dari ERP (Effective Radiated Power) atau area dimana sinyal dari antena microwave terdistribusi secara efektif. Untuk itu harus dihitung area Fresnel agar bersih dari segala obstacle.

Ketinggian antenna adalah tinggi antenna diukur dari permukaan laut

Ketinggian antenna $=$ tinggi antenna + elevasi bumi pada posisi antenna tersebut.

Dengan menggunakan perhitungan di atas maka telah dilakukan kalkulasi ketinggian antenna untuk 3 alternatif jalur.Dari hasil perhitungan tersebut dapat dihitung bahwa ketinggian antenna pada sisi pengirim telah ditentukan dengan asumsi ketinggian tersebut sama. Jika ketinggian antenna tidak sama maka dibutuhkan aplikasi Pathloss melakukan kalkulasi ketinggian antenna pada kedua 
sisi karena aplikasi Pathloss memperhitungkan kontur tanah dari kedua site tersebut.

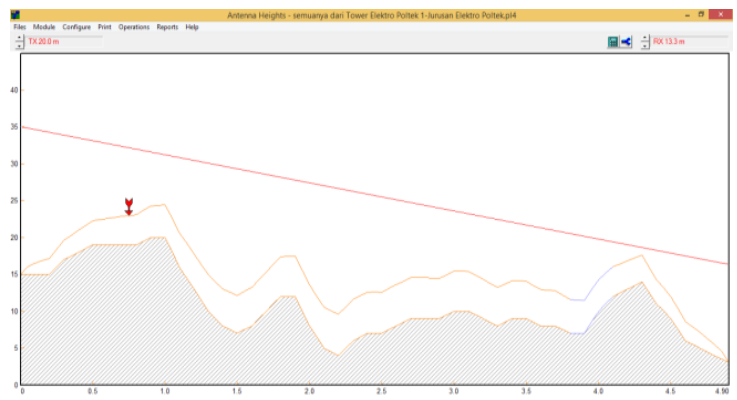

Gambar 4.5 Penentuan ketinggian antena Jalur 3 pada kedua sisi

Hasil perhitungan ini akan dibandingkan dengan hasil kalkulasi Software Pathloss yang terlihat pada profile Line of Sight.

\section{Profile Line of Sight}

Profile Line of Sight dengan menggunakan aplikasi Pathloss dapat dilakukan dengan cara menginput garis lintang dan bujur, ketinggian dari permukaan laut, Tx Power, frekuensi maka dapat hasilkan kondisi LOS pada kedua jalur tersebut. Print profile untuk menampilkan hasil LOS atau tidaknya suatu link transmisi.

1) Jalur 1

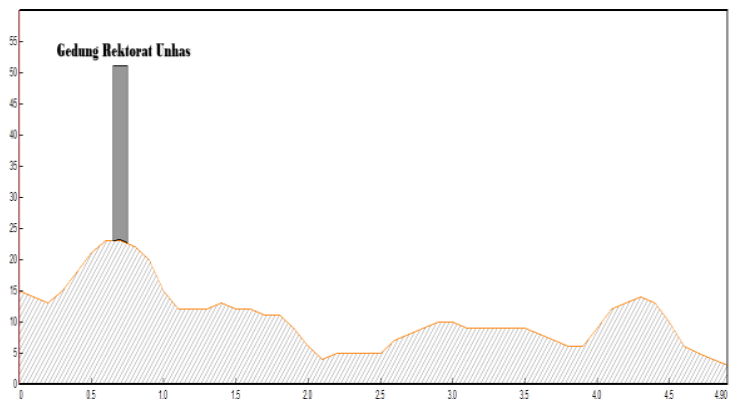

Gambar 4.6 Terrain Data Jalur 1

Dari kedua gambar di atas setelah mengisi semua informasi yang dibutuhkan pada data Summary kemudian masuk pada module Terrain Data lalu memilih menu kontur tanah secara otomatis dapat terlihat jarak di antara keduanya yaitu 4.90 dan yang menjadi penghalang yaitu Gedung Rektorat Unhas dengan ketinggian sekitar $28 \mathrm{~m}$ yang di input secara manual.

Setelah memperoleh kontur tanah dan memasukkan penghalang pada terrain data maka ketinggian antena minimum secara otomatis sudah didapat serta path profile dengan kondisi LoS dari Software Pathloss.

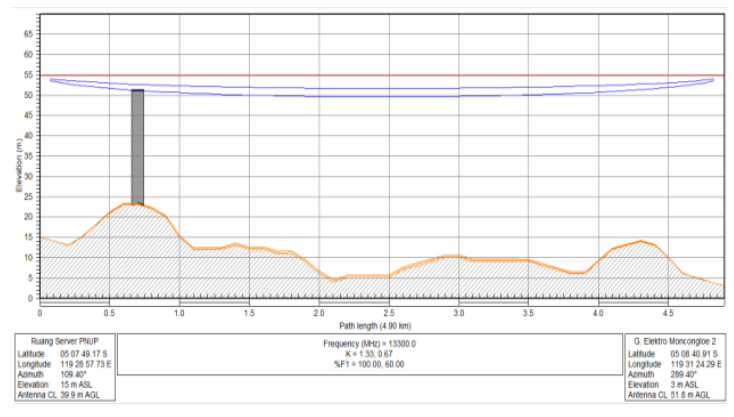

Gambar 4.7 Kondisi LOS Jalur 1

Gambar 4.7 menjelaskan bahwa dari hasil analisa Line of Sight oleh aplikasi Pathloss dengan ketinggian antena yang sama (lurus) maka disisi pengirim yaitu Ruang Server Kampus 1 ketinggian antena sekitar $54.9 \mathrm{~m}$ dan tinggi antenna $39.9 \mathrm{~m}$. Dengan demikian, ketinggian antenna disisi penerima Elektro Kampus 2 sekitar $54.9 \mathrm{~m}$ juga. Dimana pada Jalur 1 terdapat penghalang berupa gedung yaitu Rektorat Unhas.

2) Jalur 2

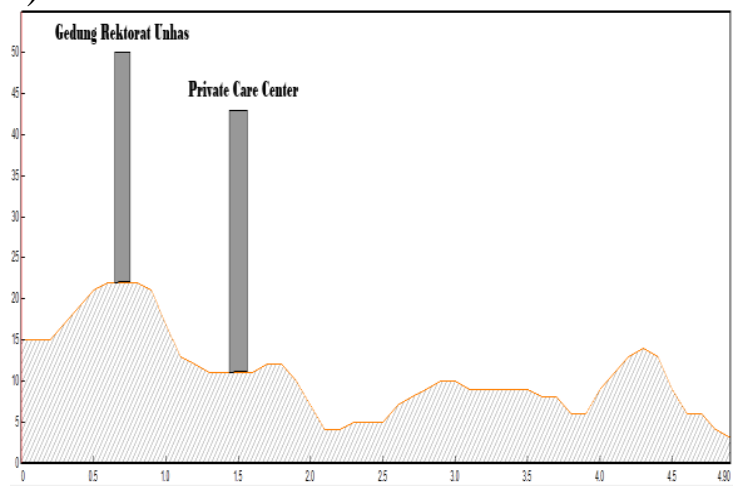

Gambar 4.8 Terrain data Jalur 2 


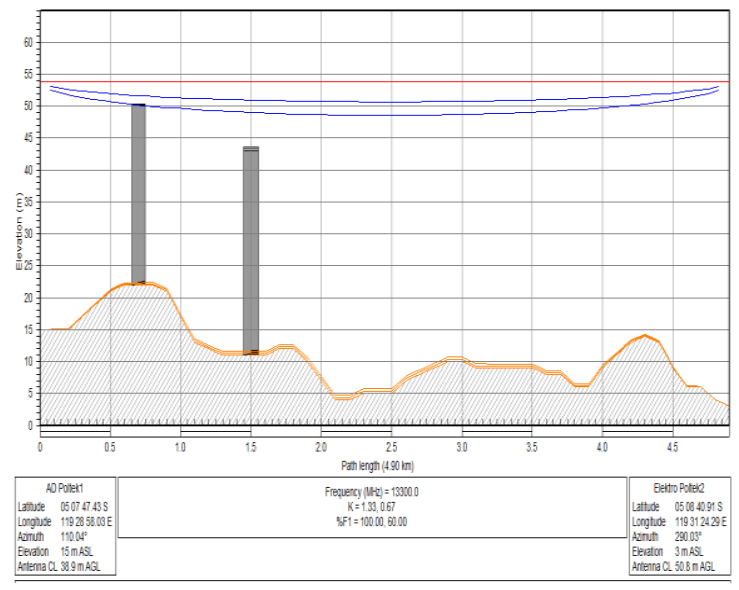

Gambar 4.9 Kondisi LOS Jalur 2

Gambar 4.9 menjelaskan bahwa dari hasil analisa Line Of Sight dengan aplikasi Pathloss dengan ketinggian antena yang sama (lurus) maka disisi pengirim yaitu Jurusan Administrasi Kampus 1 ketinggian antena sekitar $53.9 \mathrm{~m}$ dan tinggi antenna $38.9 \mathrm{~m}$. Dengan demikian, ketinggian antenna disisi penerima Elektro Kampus 2 sekitar $53.9 \mathrm{~m}$ juga. Jalur 2 dimana ada dua bangunan tinggi yang dilaluinya dengan kata lain yang menjadi penghalang di kedua jalur tersebut yaitu tinggi Gedung Rektorat Unhas $28 \mathrm{~m}$ dengan ketinggian kontur bumi $22 \mathrm{~m}$ dan tinggi Gedung Private Care Center (PCC) $32 \mathrm{~m}$ dengan ketinggian kontur bumi $11 \mathrm{~m}$.

\section{3) Jalur 3}

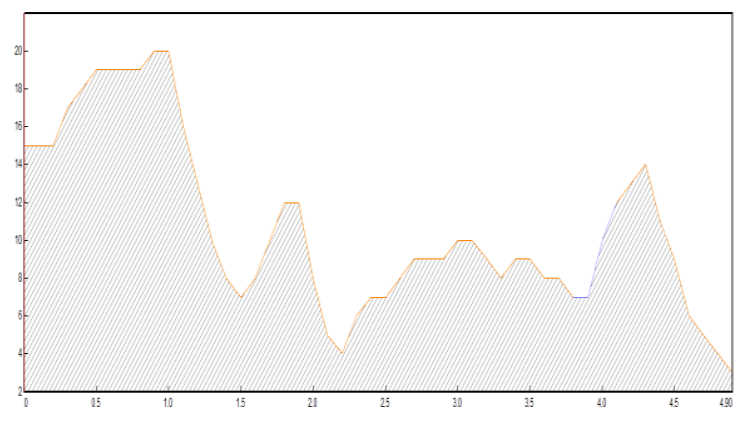

Gambar 4.10 Terrain data Jalur 3

Dari Gambar 4.10 terlihat bahwa tidak terdapat gedung sebagai penghalang pada
Jalur 3 ini. Gambar 4.10 menjelaskan bahwa pada daerah sekitar Tower Elektro Kampus 1 kontur tanahnya lebih tinggi jika dibandingkan dengan kontur tanah yang ada pada Kampus 2 Moncongloe. Di jalur tersebut tidak ada penghalang berupa gedung namun terdapat kontur tanah yang sangat tinggi yaitu $22 \mathrm{~m}$ di Fakultas MIPA Unhas yang juga menjadi penghalang pada jalur ini.

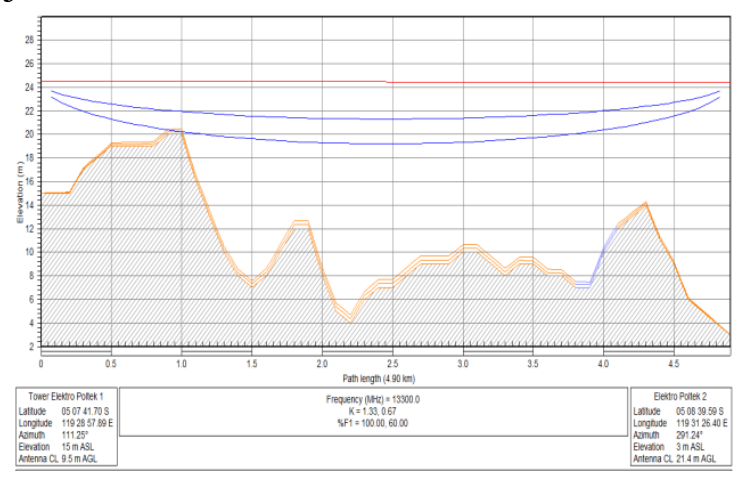

Gambar 4.12 Kondisi LOS Jalur 3 dengan ketinggian antenna sudah ditentukan

Dari perhitungan manual dan aplikasi Pathloss, maka dapat disimpulkan bahwa untuk jalur 3 tidak perlu lagi membangun tower untuk penempatan antena baik pada sisi Kampus 1 dan juga pada Kampus 2. Di Jurusan Elektro Kampus 1 sudah terdapat tower yang tingginya sekitar $20 \mathrm{~m}$ dan tinggi Gedung Jurusan Elektro Kampus 2 mencapai sekitar $10 \mathrm{~m}$ sedangkan ketinggian antenna yang dibutuhkan disisi penerima hanya $13.3 \mathrm{~m}$ sehingga lebih efisien karena tidak perlu membangun tower, cukup menggunakan tiang saja dipasang pada puncak gedung sepanjang 3,3 m untuk menempatkan ODU (Outdoor Unit) Microwave.

Dari analisa LoS diatas dapat ditentukan bahwa jalur yang terbaik sebagai jalur link microwave antara Kampus 1 dan Kampus 2 PNUP adalah jalur 3. 
Selanjutnya akan dianalisa kondisi komunikasi jika menggunakan jalur 3 dengan menghitung Link Budget komunikasi.

\subsection{Analisa Link Budget}

\subsubsection{Perhitungan Manual Link Budget dengan rumus}

\section{Free Space Loss}

Perhitungan Free Space Loss secara manual diperoleh hasil yaitu $128.74 \mathrm{~dB}$ sedangkan untuk perhitungan menggunakan Software Pathloss hasil yang didapatkan tidak jauh berbeda yaitu $128.75 \mathrm{dBm}$

\section{EIRP}

Untuk perhitungan EIRP secara manual dan perhitungan dengan menggunakan Software Pathloss maka hasil yang di dapat sama yaitu $45.6 \mathrm{dBm}$

\section{Receive Signal Level}

Untuk perhitungan RSL secara manual hasil yang di dapat yaitu $-57.54 \mathrm{dBm}$ sedangkan untuk perhitungan menggunakan Software Pathloss hasil yang didapatkan tidak jauh berbeda yaitu $57.65 \mathrm{dBm}$.

\section{System Operating Margin}

SOM (System Operating Margin) untuk meyakinkan bahwa sistem yang dirancang akan bekerja secara benar. Pada dasarnya SOM (System Operating Margin) menghitung selisih antara sinyal yang di terima dengan sensitifitas penerima.

$$
\begin{gathered}
\mathrm{SOM}=\mathrm{Rx} \text { signal level }-\mathrm{Rx} \text { sensitivity } \\
=-57.54-(-70) \\
=12.46 \mathrm{~dB}
\end{gathered}
$$

SOM standar yang menunjukkan kualitas komunikasi yang baik sesuai standar IEEE yaitu antara 10-15 dBm

\subsubsection{Perhitungan Link Budget dengan Pathloss}

Pada Software Pathloss diinput data lintang, bujur, ketinggian dari permukaan laut dan penghalang antara titik awal dan titik akhir pada ketiga jalur yang sudah di dapatkan dari Google Earth, menentukan ketinggian tower, TX Antenna Height, TX loss, RX Antenna Height, RX loss, Radio model, TX Power dari perangkat radio model yang digunakan serta frekuensi.

Aplikasi menampilkan hasil link budget yang dibutuhkan untuk dijadikan acuan implementasi atau proses instalasi perangkat. Pilih menu m;8odule, Worksheet, Report, dan pilih Full Report.

Hasilnya sebagai berikut :

\section{Link Bugdet untuk jalur 3}

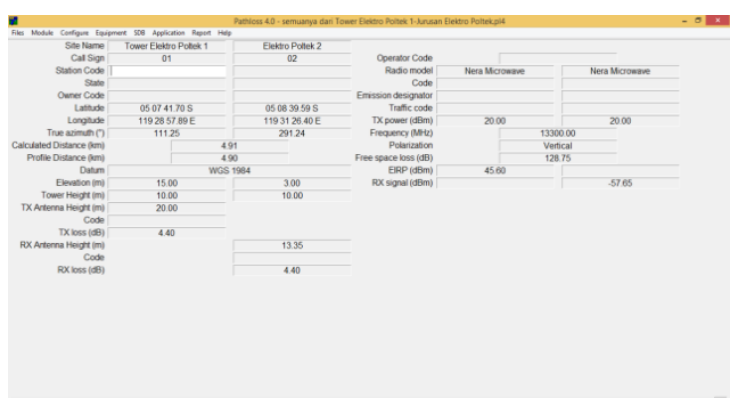

Gambar 5.13 Hasil Link Budget Jalur 3 menggunakan Aplikasi Pathloss

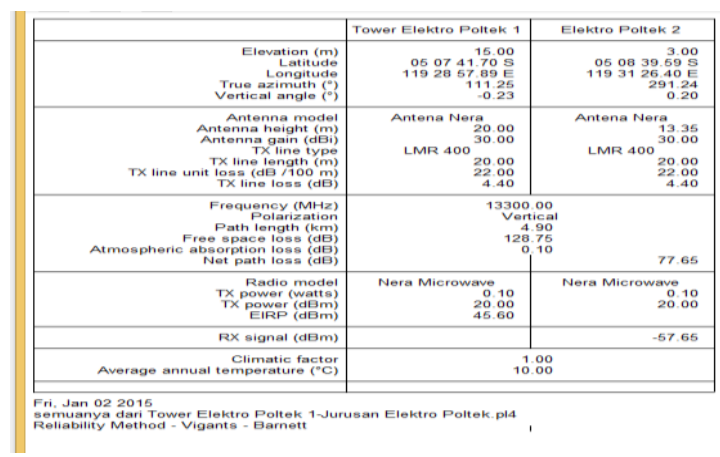

Gambar 4.14 Full Report dari Pathloss

Dari keseluruhan hasil analisa dan perhitungan diatas dapat dibandingkan 
bahwa dengan menggunakan Antena Nera Microwave dengan frekuensi $13.3 \mathrm{GHz}$ menghasilkan kualitas komunikasi jalur antar Kampus 1 dan Kampus 2 Moncongloe dengan nilai $\mathrm{SOM}=12.46$ dB. SOM standar yang menunjukkan kualitas komunikasi yang baik sesuai standar IEEE yaitu $10-15 \mathrm{dBm}$.
Berikut hasil desain Desain Infrastruktur Jaringan Link Microwave antar Kampus Politeknik Negeri Ujung Pandang disertai dengan tingkat performansi kualitas komunikasi yang akan dihasilkan berdasarkan hasil analisa dalam penelitian ini :

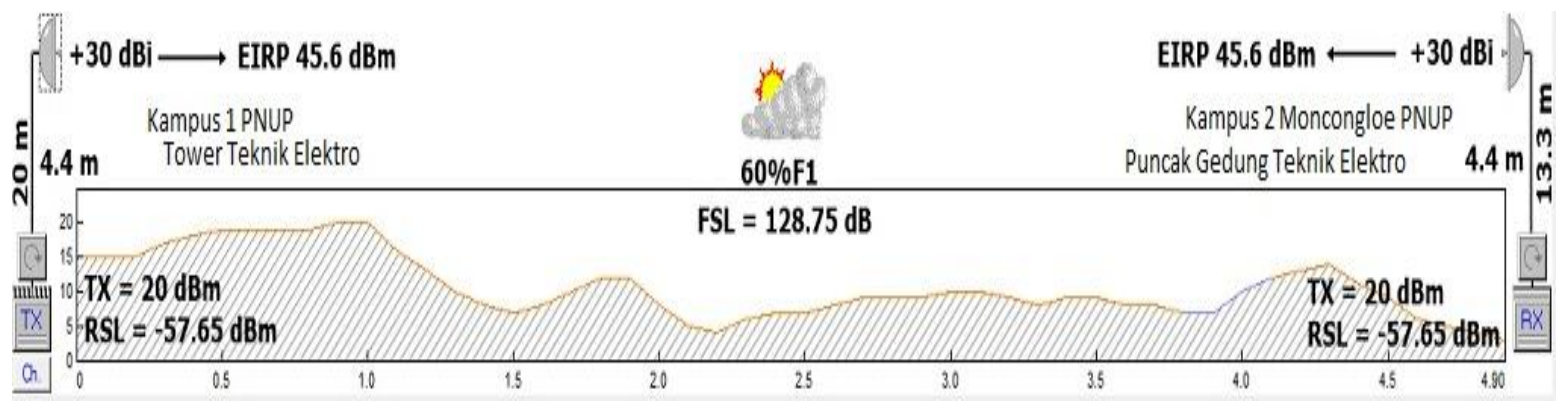

Gambar 4.15 Hasil Desain Jaringan Microwave antar kampus

Politeknik Negeri Ujung Pandang

\section{KESIMPULAN}

1) Dari hasil analisa link Microwave antara Kampus 1 dan Kampus 2 yang berjarak 4,9 Km, ditetapkan lokasi titik awal di area Jurusan Elektro Kampus 1 dan titik akhir di Gedung Jurusan Elektro Kampus 2. Jalur tersebut memenuhi kriteria Line of Sight dan bebas dari penghalang serta efisien dalam pengadaan infrastruktur. Desain ketinggian antenna atau tower Jurusan Elektro Kampus 1setinggi $20 \mathrm{~m}$ dan titik akhir di Puncak Gedung Jurusan Elektro Kampus 2 setinggi 13,35 m, cukup menggunakan tiang setinggi $3,35 \mathrm{~m}$.

2) Performansi komunikasi melalui jalur link Microwave tersebut diatas memiliki kualitas yang sangat baik dimana parameter komunikasi terpenuhi adalah : FSL $128.75 \mathrm{~dB}$, EIRP 45.60 $\mathrm{dBm}, \quad \mathrm{RSL}-57.65 \mathrm{dBm}, \quad$ SOM 12.46 $\mathrm{dB}$

\section{Daftar Pustaka}

[1]. BAN-PT, 2007, Kumpulan Instrumen Standar 11 Sistem Informasi Institusi Perguruan Tinggi, Departemen Pendidikan Nasional.

[2]. Marissa, D. 2012, Enterprise Architecture Planning untuk Pengembangan Sistem Informasi Perguruan Tinggi, Program Pascasarjana Universitas Diponegoro Semarang.

[3]. Utami,R Hikmaturrokhman, A, Fitrian, A, Analisis Link Budget Jaringan Microwave dengan Menggunakan Pathloss 5.0., Prosiding JHPTUMP 2014

[4]. Yunis, R dan Surendro, K, 2009, Model Enterprise Architecture untuk Perguruan Tinggi, Prosiding SemnasIF 2009 Vol. 3, No.1:pp A53-A59. 